\title{
THE ROLE OF STAFFING AND ORIENTATION PRACTICES IN PREDICTING SERVICE-ORIENTED ORGANISATIONAL CITIZENSHIP BEHAVIOUR
}

\author{
Aizzat Mohd. Nasurdin'1, Noor Hazlina Ahmad² and Cheng Ling Tan ${ }^{3^{*}}$ \\ ${ }^{1,2}$ School of Management, Universiti Sains Malaysia, \\ 11800 USM Pulau Pinang, Malaysia \\ ${ }^{3}$ Graduate School of Business, Universiti Sains Malaysia, \\ 11800 USM Pulau Pinang, Malaysia \\ *Corresponding author: tanchengling@usm.my
}

Published online: 30 December 2016

To cite this article: Mohd. Nasurdin, A., Ahmad, N. H., Tan, C. L. (2016). The role of staffing and orientation practices in predicting service-oriented organisational citizenship behaviour. Asian Academy of Management Journal, 21(2), 27-51. http://dx.doi.org/ 10.21315/aamj2016.21.2.2

To link to this article: $\mathrm{http} / / \mathrm{dx}$.doi.org/10.21315/aamj2016.21.2.2

\begin{abstract}
This study examined the relationships between two specific human resource management practices (staffing and orientation) and service-oriented organisational citizenship behaviour. Survey data were gathered from a sample of 290 frontline employees attached to 4-and 5-star hotels in Malaysia. The partial least squares technique was used to test the research hypotheses. Results showed that staffing (consisting of recruitment and selection) and orientation have positive effects on the three dimensions of service-oriented organisational citizenship behaviours. These findings demonstrate the need for hotels to revisit their prevailing staffing and orientation practices in an attempt to enhance their employees' display of service-oriented citizenship behaviours.
\end{abstract}

Keywords: service-oriented organisational citizenship behaviours, staffing, recruitment, selection, orientation. 


\section{INTRODUCTION}

Malaysia is gifted with a diverse range of natural attractions, historical monuments, ancient settlements, and unique landmarks of world standard. In addition, the country is blessed with an exotic blend of cultures due to its multi-racial population. These attractions are an asset to Malaysia's tourism industry. In its effort to place Malaysia in the world tourism destination map, various strategies have been undertaken by the government which includes increasing tourism promotions through a multitude of campaigns, programs, and events as well as upgrading of tourism-related facilities. "Malaysia Truly Asia" is the tagline which has been internationally recognised as a unique Malaysian brand to promote the country's tourism sector. Although the tourism industry in Malaysia started since the early 1970s, the starting point for the industry actually began in 1990 with the Visit Malaysia Year Campaign. The success of this campaign has resulted in an overwhelming growth in the number of tourist arrivals to Malaysia of 7.45 million compared to 4.85 million in 1989 (Ministry of Tourism and Culture Malaysia, 2015). Over the past two decades, the tourism industry continued to expand. By 2012, tourist arrivals to Malaysia amounted to 25.03 million (Ministry of Tourism and Culture Malaysia, 2014).

The healthy growth of the tourism trade has encouraged the private sector to invest more in tourism-related infrastructures and services. This is illustrated by the increase in the number of hotels by 51.2\% from 1568 in 2003 to 3094 in 2013 (Tourism Malaysia, 2014). As a result, service providers within the hospitality industry have to compete more aggressively to survive and maintain their competitive edge. Given that the variations among the products and facilities offered by hotels are marginal, $\mathrm{Ma}$ and Qu (2011) suggested that the key for hotels to sustain their competitive advantage in today's marketplace would be through the provision of outstanding service quality to their customers. In this regard, frontline employees play a fundamental role since they serve as "boundary spanners". According to Yoon and Suh (2003), the attitudes and behaviors of these employees have a significant influence on customers' perceptions of service quality. Hence, service organizations should pay attention to their behaviors in an attempt to enhance service quality. This point of view is well supported by scholars who contend that frontliners' behaviors significantly affect customers' perceived service satisfaction (Bienstock, DeMoranville, \& Smith, 2003; Karatepe \& Uludag, 2008; Yang, 2011). In the hospitality industry, the creation and provision of services to the customers are primarily achieved through employees (Maroudas, Kyriakidou, \& Vacharis, 2008). Thus, employees are considered an indispensable asset for hotels to achieve their business goals (Hayes \& Ninemeier, 2009). 
There are many forms of behaviour that could contribute to a customer's perception of excellent service. Since frontline employees are involved in the service delivery process that frequently deals with an array of customers' demands and expectations, many of their behaviours cannot be fully specified in advance. For instance, frontline employees, who assist their colleagues who are temporarily burdened with work, provide informal mentoring to less skilled staff, and demonstrate courtesy and acts of goodwill to customers, can be said to contribute to superior service. Organ (1988) termed these extra work-related behaviors as organizational citizenship behavior (hereafter labeled as OCB). According to Organ (1988), OCBs are behaviors that extend beyond those specified by formal job descriptions and measured by formal appraisals. For service organizations that have unique prerequisites in dealing with customers, Bettencourt, Gwinner, and Meuter (2001) proposed that serviceoriented OCBs (henceforth labeled as service-oriented OCBs), a specific form of $\mathrm{OCB}$, is more appropriate in measuring OCBs of service employees. Specifically, service-oriented OCBs comprise three dimensions of loyalty OCBs, participation OCBs, and service delivery OCBs.

Given the advantages of displaying service-oriented OCBs in service firms, a lot of studies have been conducted to investigate how to elicit service-oriented OCBs. Some of the variables of focus include perceived organizational support (Lin \& Lin, 2011; Wang, 2009a; 2009b), leadership (González \& Garazo, 2006; Tsai \& $\mathrm{Su}, 2011$ ), and human resource management practices (Nasurdin, Tan, \& Low, 2011; Sun, Aryee, \& Law, 2007; Tang \& Tang, 2012; Wang, 2010; Yang, 2011). Kusluvan, Kusluvan, Ilhan, and Buyruk (2010) highlighted human resources as the primary driving force in hospitality organizations since their chief output is services. Kusluvan et al., (2010) further advocated that the treatment and management of employees should be a crucial concern for managers in the hospitality sector. In this regard, designing a context that can bring about higher levels of service-oriented OCBs is one way to ensure the creation of value for customers and profitability for organisations. According to Morrison (1996), an organization's approach to human resource management (HRM) is instrumental in generating greater levels of OCBs, which in the aggregate, will have a positive effect on the quality of service that an organization delivers. In fact, Hoque (1999) demonstrated that hotels that adopted HRM practices with a primary focus on quality enhancement exhibited superior performance.

Several authors (Boon, Belschak, Den Hartog, \& Pijnenburg, 2014; Morrison, 1996; Snape \& Redman, 2010) reasoned that the manner in which an organization manages its human resources will establish the tone and conditions for the employee-employer relationship. To the extent that an organization's HRM 
practices create a social exchange relationship (Blau, 1964), employees are more likely to engage in functional behaviors that go beyond their call of formal duty, such as OCBs. Wayne, Shore, and Liden (1997) argued that employees are likely to interpret certain HR decisions and practices as indicative of organizational support. In line with Blau's (1964) social exchange theory, Wayne et al. (1997) suggested that employees who feel that they have been well supported by their organization tend to reciprocate by performing better and engaging more readily in discretionary behaviors such as OCBs. Although researchers have provided some empirical evidence on the effects of HRM practices on service-oriented OCBs, Tang and Tang (2012) noted that such investigations within the hotel industry are still limited. In addition, very little is known about service-oriented OCBs within the context of Malaysia except for the study by Nasurdin et al. (2011). In their investigation, Nasurdin et al. (2011) focused on the effects of individual HRM practices on service-oriented OCBs of employees within the logistic industry. It has been argued that employees' perceptions of their organization's individual HRM practices are crucial in influencing their attitudes and behaviors (Allen, Shore, \& Griffeth, 2003; Whitener, 2001). Although there are two primary perspectives of HRM, the "universal" or the "best practice" approach has received more empirical support than the "contingency" approach (Huselid, 1995). Researchers that embrace the former approach claim that some HR practices are always better than the others (Delery \& Doty, 1996). Of the several HRM practices discussed in the literature, two specific HRM practices have been earmarked as having the potential to greatly affect employees' attitudes and behaviours. These specific HRM practices are staffing and orientation. Staffing (which entails recruitment and selection) can result in satisfied and committed employees (Riordan, Weatherly, Vandenberg \& Self, 2001; Verquer, Beehr, \& Wagner, 2003). Meanwhile, orientation facilitates new employees' adjustment and their subsequent confidence and motivation (Allen \& Meyer, 1990; Cooper-Thomas \& Anderson, 2006). Based on this gap, the significant contribution of the hotel industry to Malaysia's revenues, the vital function performed by frontline employees in delivering services to their customers, and in the interest of parsimony, the present study aims to examine the effects of these two HRM practices (staffing and orientation) on service-oriented OCBs among frontline hotel employees in Malaysia.

\section{LITERATURE REVIEW}

\section{Service-Oriented Organisational Citizenship Behaviours (OCBs)}

The nature of work for employees working in service organizations is different from those working in non-service organizations such as manufacturing. In service 
organizations, frontline employees that have direct interactions with customers become part of the product, represent the organization, and assist in forming the image of the organization (Hartline \& Jones, 1996). In fact, Kusluvan et al. (2010) stated that it is the personality, appearance, attitudes, and behaviors of these employees that facilitate the conversion of the intangibility of services into something tangible. Based on the unique work requirements of service organizations, Bettencourt, Gwinner, and Meuter (2001) reasoned that there is a need to further refine the general OCB construct to include more specific forms of OCBs. Bettencourt et al. (2001) in their study proposed the term service-oriented OCBs for such behaviors, which consist of three dimensions: (1) loyalty OCBs; (2) service delivery OCBs; and (3) participation OCBs. Loyalty OCB refers to behaviours concerning acting as advocates to outsiders not only of the organisation's products and services but also of its image. Meanwhile, participation OCB involves actions such as taking individual initiative, especially in communications to improve their own service delivery and that of their organisation and peers. Finally, service delivery OCB refers to employees behaving in a conscientious manner when delivering their services to customers. Several researchers deemed service-oriented OCBs as more fitting for service organizations (Wang, 2009a; 2009b; Wang, 2010; Tang \& Tang, 2012).

\section{Human Resource Management (HRM) Practices}

Generally, HRM involves personnel policies and managerial practices and systems that influence the workforce (Bernardin \& Russell, 2007). A more focused definition was offered by Mathis and Jackson (2000) whereby HRM relates to the design of formal systems in an organization to ensure an effective and efficient use of human talent to accomplish organizational goals. Based on these thoughts, it can be surmised that HRM practices relate to specific practices, formal policies, and philosophies that are designed and implemented to attract, develop, motivate, and retain employees for the effective functioning of an organisation. According to Mathis and Jackson (2000), HRM activities involve several key areas such as human resource planning and analysis, staffing, human resource development, compensation and benefits, health, safety, and security, and employee and labor/management relations. As previously mentioned, HRM practices enable organizations to create a positive social exchange relationship with employees, which ultimately motivate them to engage in favorable behaviors. The hospitality industry is labor-intensive (Solnet \& Hood, 2008). Hoque (1999) asserted that in such industry where there is mounting pressure to adopt a business strategy that emphasizes quality, flexibility, and innovation, an HRM approach will be universally relevant (Hoque, 1999). In the case of hotels, where the emphasis is on the provision of superior quality and customised services, deploying HRM 
practices that focus on employees' abilities to respond quickly to customers' needs and desires would prove to be an effective move.

A review of the hospitality literature by Kusluvan et al. (2010) indicates the emergence of two streams of research on HRM practices. The first stream examined individual HRM practices whereas the second stream was devoted to studies on the effects of bundles of HRM practices. Studies in both streams concluded that individual or bundles of HRM practices in the hospitality industry are still underdeveloped as opposed to other industries (Kusluvan et al., 2010). Hence, there is still a need for more investigations on HRM practices within this particular sector. It has been argued that HRM practices implemented at the point of entry into an organisation are critical in nurturing new employees' beliefs about the tone of the employee-employer relationship. According to Morrison (1996), a selection process that emphasizes broadly defined obligations and long-term commitment conveys to prospective employees that they are entering into a social exchange relationship. In addition, a selection process that entails selecting employees on the basis of how well they fit into the overall organisation's culture will ensure a person-organisation fit, leading to greater satisfaction and retention. Similarly, as noted by Morrison (1996), a socialization process which occurs after a new employee joins an organization can help channel information to new recruits that their employer is committed to building a social exchange relationship. Through the execution of formal orientation programs, new employees can learn and identify themselves with organizational goals and values, which in turn, stimulate them to engage in OCBs.

In a similar vein, as argued by Wayne, Shore, and Liden (1997), given that employees are likely to perceive the use of HRM practices as an indicator of organizational support, a positive employee-employer exchange relationship is likely to be initiated, which in turn, lead to greater work performance and other forms of extrarole behaviors including service-oriented OCBs. Due to the inconclusive debate on what constitutes appropriate HRM activities particularly for hotels and for the purpose of developing a parsimonious research model, in the present study, we opted to focus on two specific practices: staffing (which entails recruitment and selection) and orientation. Since high employee turnover is a major problem in the hotel industry (Kusluvan et al., 2010) and also within the context of the Malaysian hotel sector (Ahmad \& Scott, 2013), the management of hotels are bound to be repeatedly engaged in staffing activities for replacement and conducting orientation program for new recruits. We contend that these two practices may influence prospective and newly recruited employees' perceptions about the hotel's concern for its employees in terms of their dispositions to better serve customers and their 
abilities to quickly adapt to their new work environment, which in turn, are likely to motivate employees to engage in service-oriented OCBs.

\section{Staffing and Service-Oriented OCB}

The aim of staffing is to provide an adequate supply of qualified individuals to fill the jobs in an organization (Mathis \& Jackson, 2000). In our study, staffing entails employees' perception of their employing hotel's recruitment and selection process. These two activities help to ensure that the organization has sufficient human resources to perform the job (Hayes \& Ninemeier, 2009). According to Vlachos (2008), staffing enables the organization to attract the right candidate with desirable characteristics in terms of knowledge, skills, and attitudes into the organization. Morrison (1996) in her conceptual article argued that to the extent that the recruitment and selection process emphasize broadly defined obligations and long-term commitments on the part of the organization and conveys to prospective employees that they are entering into a social exchange relationship (Blau, 1964), employees will engage in more OCBs.

From the organisation's standpoint, staffing through recruitment and selection can influence the exhibition of employees' service-oriented OCBs in two ways. First, staffing enables the organisation to have adequate manpower to perform the job. Staff shortages are often linked to problems in delivering excellent service (Ahmad \& Scott, 2013). For instance, a manpower shortage at the hotel's checkin counter may result in longer waiting time for customers during the check-in process. As a result, frontline employees who are temporarily loaded with work due to staff shortage may not be able to display behaviours that surpassed their role prescriptions such as service-oriented OCBs, which would have a favourable impression on the customers. Instead, these workers would probably devote their energies to perform their basic formal duties. However, when efficient staffing is in place, hotels would have an ample number of employees to deliver the services to customers. In such situations, employees who are on duty would be able to assist their colleagues at the counter in attending to a customer's requests. Through their discretionary extra-role service-oriented behaviours, the waiting time for customers would be significantly reduced. Second, selective hiring which suggests rigorous recruitment of the right employee that fits well into the organization's culture would enhance employee attachment to the organization (Fiorito, Bozeman, Young, \& Meurs, 2007), which will ultimately have a favorable effect on customers' perception of the organization's service quality. A meta-analysis by Verquer et al. (2003) showed that selective recruitment leads to the creation of satisfied and committed employees. Bettencourt et al., (2001) further demonstrated 
that service-oriented OCBs are likely to occur if employees have developed a positive affect towards their organization. In other words, when hotels implement effective staffing, their employees would experience higher job satisfaction and greater organisational commitment. As a result, these positive attitudes would motivate employees especially those at the frontlines to go beyond their call of duty by performing service-oriented OCBs. Tsaur and Lin (2004) provided empirical support for the positive influence of staffing components (i.e. recruitment and selection) on frontline hotel employees' attitudes and behaviors in Taiwan. From customer-contact employees' point of view, a recruitment and selection process that emphasizes traits and abilities associated with superior service delivery would convey the message that such dispositions are highly valued by the organisation. Within the hotel setting, such employees would be more likely to understand and anticipate customer's needs and expectations and be more effective in publicising the hotel and its service offerings (i.e. loyalty OCB), be more likely to offer more service improvement ideas for the hotel (i.e. participation OCB), and be more able to succeed in dispensing superior service to customers (i.e. service delivery OCB). Likewise, a recruitment process that provides greater opportunities for internal promotion would alleviate customer-contact employees' motivation and satisfaction, which in turn, encourages them to reciprocate the hotel's supportive practices by engaging in voluntary behaviours that benefit the hotel. Hence, it is expected that these employees would be more likely to exhibit service-oriented OCBs of loyalty, participation, and service delivery. Hence, we hypothesised that:

H1: Staffing will be positively related to the SOOCBs.

H1a: Staffing will be positively related to loyalty OCBs.

H1b: Staffing will be positively related to participation OCBs.

H1c: Staffing will be positively related to service delivery OCBs.

\section{Orientation and Service-Oriented OCB}

Orientation is the process of providing basic information about the organization that must be known by all staff members (Hayes \& Ninemeier, 2009). Specifically, the purpose of orientation is to provide an overview of the organization to the newcomers, indicate their roles in the organization, familiarize them to the policies and rules of the organization, provide information on employees' benefits, outline specific employer's expectations, as well as to motivate them to perform well in order to achieve the goals of the organization (Hayes \& Ninemeier, 2009). Generally, new recruits that joined an organization do not know what they are supposed to do 
and how they are supposed to behave or even where they are supposed to be at any given time (Tanke, 2001). As a consequence, orientation enhances an employee's job confidence, motivation, and enthusiasm (Cooper-Thomas \& Anderson, 2006; Wanous \& Reichers, 2000). Likewise, according to Louis (1980), orientation assists newcomers to adapt themselves into the organization. When new employees are able to adapt quickly to the new environment, they are more likely to experience lower anxiety, thereby, enabling them to become more motivated and committed in their jobs. Within the service sector, a study by Riordan et al. (2001) on bank employees in the South-Eastern United States provided empirical evidence to support the positive impact of socialization tactics on employees' attitudes such as satisfaction, commitment, and turnover intentions. Committed employees are likely to perform their job well and be more willing to expend extra effort for the sake of the organization. Klein and Weaver (2000) discovered that satisfied and committed employees tend to display more service-oriented OCBs. As mentioned before, a socialization process can help new employees identify themselves with organizational goals (Morrison, 1996). According to Morrison (2000), formal orientation may be able to increase new employees' awareness and understanding of the organization's values and goals. In such situation, these new workers would become inspired to adhere to their role expectations, and hence, more likely to engage in behaviours that go beyond their formal job descriptions. Similarly, through orientation programs, new employees learn about the organisation and its commitment to establish a long-term employer-employee relationship. In social exchange relationships (Blau, 1964), these employees may felt obliged to reciprocate the organization through voluntary service-oriented OCBs. In the hotel industry, customer-contact employees who understand their work roles and the values and goals of their organization are more likely to be able to be more active in promoting the hotel and its service (i.e. loyalty OCB), be more likely to become involved in activities aimed at improving the hotel's service orientation (i.e. participation $\mathrm{OCB}$ ), and be more effective in serving customers (i.e. service delivery OCB). Taking stock of the above discussion, we postulated that:

H2: Orientation will be positively related to the service-oriented OCBs.

H2a: Orientation will be positively related to loyalty OCBs.

$\mathrm{H} 2 \mathrm{~b}$ : Orientation will be positively related to participation OCBs.

H2c: Orientation will be positively related to the service delivery OCBs. 


\section{METHODOLOGY}

\section{Sample and Data Collection Procedure}

Our participants consisted of customer-contact employees attached to the frontoffice department of 29 large hotels located in three regions of Peninsular Malaysia. Our study focused on the front-office department because employees in this particular department will be in direct communicative and selling position with customers as remarked by Baum and Devine (2007). A total of 128 hotels with 4 and 5-star ratings were identified from the directory of hotels in Malaysia published by the Ministry of Tourism (2012). Following Ekiz, Khoo-Lattimore, and Memarzadeh (2012), we selected 4 and 5-star rated hotels because these hotels are considered large and have a more systematic and organized HR department. Of these, only 29 hotels consented to participate. We employed the "drop-off" and "pick-up" method to distribute our survey packets for 14 hotels in the northern region. For the remaining 15 hotels located in other regions, survey packages were sent and collected via mail. Each survey packet addressed to the HR managers of the respective hotels contained 10 questionnaires to be distributed to customer-contact employees working in the front office department. Two weeks were accorded to the employees to complete and return the questionnaire to their front office manager who was responsible for returning them to the HR manager. After the two-week stipulated period, 290 questionnaires were received. Of these, 150 questionnaires were obtained through the mail and the remaining 140 questionnaires were personally collected by the researchers. All these questionnaires were found to be useable and subjected to further analysis.

\section{Measures and Analysis}

A questionnaire using a five-point Likert scale ("1" = "strongly disagree" to "5" = strongly agree") was used to gather data. Staffing (consisting of recruitment and selection) was gauged using 5 items adapted from Chuang and Liao (2010), whereas orientation was measured using 4 items adapted from previous sources (Rogg, Schmidt, Shull, \& Schmitt, 2001; Chang \& Chen, 2011; Atteya, 2012). Meanwhile, service-oriented OCBs were assessed via 16 items adapted from the scale developed by Bettencourt et al. (2001) which include loyalty (5 items), participation ( 5 items), and service delivery (6 items). The measurement items for each variable in this study are provided in Appendix A. In the present study, the use of self-report in measuring service-oriented OCBs was considered appropriate since OCB occurrences may not be readily visible to alternative rating sources (such as supervisors and peers), based on the suggestion made by Organ and Konovsky (1989). 
Bearing in mind that demographic variables (such as age, gender, ethnicity, academic qualification, marital status, job tenure, and organization tenure) were found to have correlations with service-oriented OCBs (Bettencourt et al., 2001; Bolino \& Turnley, 2005; Fiorito et al., 2007; Nasurdin et al., 2011; Ramachandran, Jordan, Troth \& Lawrence., 2011; Wang, 2009a), we statistically controlled these variables to avoid overestimating the effect of the exogenous variables on the endogenous variables.

Our hypotheses were tested using the Partial Least Squares (PLS) method. The objective of Partial Least Square-Structural Equation Modeling (PLS-SEM) is to maximise the explained variance of the endogenous latent variable by estimating the structural model relationships (Hair, Ringle, \& Sarstedt, 2011). PLS-SEM, a second generation technique, was employed to overcome the weaknesses of the first generation techniques (such as multiple regression). This method enables the incorporation of unobserved variables which were measured indirectly by indicator variables. It also facilitates accounting for measurement error in observed variables (Chin, 1998).

The analysis of the research model was conducted by separately examining the measurement model and the structural model. Evaluation of the measurement model was to gauge the reliability and validity of the model. On the other hand, evaluation of the structural model involved testing the significance of the path coefficients and $\mathrm{R}^{2}$ measures.

\section{RESULTS}

\section{Descriptive Results}

Of those who completed the survey, 177 (61.0\%) were females and $113(39.0 \%)$ were males. In terms of ethnicity, the sample consisted of Malays (69.0\%), Chinese $(18.3 \%)$, Indians $(11.7 \%)$, and others $(1.0 \%)$. In terms of academic qualification, a majority of the respondents were secondary school leavers (72.1\%). Almost half of the sampled employees were married $(44.1 \%)$. The mean age for the sample was 27.5 years. In terms of job experience, on average, respondents have worked as customer-contact employees for 4.3 years and in the hotel for about 4.4 years.

Descriptive statistics for our variables of study are presented in Table 1. Staffing (comprising recruitment and selection) and orientation had moderate mean values of 3.85 and 3.91 respectively, with a standard deviation of 0.64 and 0.66 . On the 
other hand, the levels of service-oriented OCBs in terms of the three dimensions are as follows: loyalty OCBs (Mean $=4.00 ; \mathrm{SD}=0.72$ ), participation OCBs (Mean=3.89; $\mathrm{SD}=0.69$ ), and service delivery OCBs (Mean=4.10; $\mathrm{SD}=0.68$ ). These values suggest that, on the average, loyalty OCBs, participation OCBs, and service delivery OCBs were moderate. The overall missing data was well below $15 \%$, hence, mean value replacement was adopted to treat data for this study (Hair, Hult, Ringle, \& Sarstedt, 2014).

Table 1

Means and standard deviations for the variables of study

\begin{tabular}{lcc}
\hline Variable & Mean & Std. Deviation \\
\hline Staffing & 3.85 & 0.64 \\
Orientation & 3.91 & 0.66 \\
Service Oriented OCBs & & \\
Loyalty & 4.00 & 0.72 \\
Participation & 3.89 & 0.69 \\
Service Delivery & 4.10 & 0.68 \\
\hline
\end{tabular}

Harman's single factor test is one of the methods to detect the existence of common method bias in a survey (Podsakoff \& Organ, 1986). Common method bias refers to the inflation of relationships due to methods effect, and it causes the observed score correlations to be inflated as compared to their true score counterpart (Coway $\&$ Lance, 2010). Our concern is whether a single latent factor contributes most to the explained variance in the dependent variable, resulting in common method bias in our study. To examine the existence of this bias, and consistent with Greene and Organ (1973), we loaded all items from each of the constructs into an exploratory factor analysis to see whether one single factor does account for a majority of the covariance between the measures; if not, it can be claimed that common method bias is not an issue. Our results revealed five distinct factors which accounted for $67.70 \%$ of the variance in the data with the first factor capturing only $20.88 \%$ of the said variance, which is less than the proposed threshold value of 50\% (Podsakoff, MacKenzie, Lee, \& Podsakoff, 2003). Hence, it can be assumed that common method bias was not a major concern in this study.

\section{Measurement Model Results}

Table 2 depicts the result for the measurement model. As can be seen, all the items' loadings ranged from 0.718 to 0.902 , which is greater than the 0.70 cut-off value suggested by Chin (1998). Likewise, the composite reliability of the constructs 
ranged from 0.909 to 0.933 , which exceeded the 0.70 ceiling value recommended by Fornell and Larcker (1981). Hence, the measurement model was considered reliable.

Table 2

Results of the measurement model

\begin{tabular}{|c|c|c|c|c|}
\hline Variable & Items & Loadings & Composite Reliability & AVE \\
\hline \multirow[t]{5}{*}{ Staffing } & hrm_staff1 & 0.812 & 0.912 & 0.676 \\
\hline & hrm_staff2 & 0.865 & & \\
\hline & hrm_staff3 & 0.880 & & \\
\hline & hrm_staff4 & 0.800 & & \\
\hline & hrm_staff5 & 0.748 & & \\
\hline \multirow[t]{5}{*}{ Orientation } & hrm_orient1 & 0.807 & 0.909 & 0.667 \\
\hline & hrm_orient2 & 0.799 & & \\
\hline & hrm_orient 3 & 0.824 & & \\
\hline & hrm_orient4 & 0.839 & & \\
\hline & hrm_orient5 & 0.816 & & \\
\hline \multirow[t]{5}{*}{ Loyalty OCB } & OCBL1 & 0.897 & 0.933 & 0.738 \\
\hline & OCBL2 & 0.902 & & \\
\hline & OCBL3 & 0.845 & & \\
\hline & OCBL4 & 0.815 & & \\
\hline & OCBL5 & 0.831 & & \\
\hline \multirow[t]{5}{*}{ Participation OCB } & OCBS6 & 0.853 & 0.917 & 0.689 \\
\hline & OCBS7 & 0.856 & & \\
\hline & OCBS8 & 0.877 & & \\
\hline & OCBS9 & 0.837 & & \\
\hline & OCBS 10 & 0.718 & & \\
\hline \multirow[t]{6}{*}{ Service Delivery OCB } & OCBS11 & 0.808 & 0.929 & 0.686 \\
\hline & OCBS12 & 0.801 & & \\
\hline & OCBS13 & 0.859 & & \\
\hline & OCBS14 & 0.786 & & \\
\hline & OCBS15 & 0.862 & & \\
\hline & OCBS16 & 0.849 & & \\
\hline
\end{tabular}

${ }^{a}$ Composite reliability $(\mathrm{CR})=$ (square of the summation of the factor loadings) $/$ ( (square of the summation of the factor loadings) + (square of the summation of the error variances) $\}$

${ }^{\mathrm{b}}$ Average variance extracted $(\mathrm{AVE})=$ (summation of the square of the factor loadings) / (summation of the square of the factor loadings) + (summation of the error variances) $\}$ 
We also examined the validity of the measurement model based on its convergent validity and discriminant validity. As depicted in Table 2, all the AVE values (ranging from 0.667 to 0.738 ) exceeded the 0.5 threshold value proposed by Fornell and Larcker (1981).

Table 3 shows that the square roots of the AVE of the latent variables exceeded the correlations of other constructs. Table 4 illustrates that the loadings of each construct were greater than all of its cross-loadings. Based on the information presented in Table 3 and Table 4, and adhering to the guideline developed by Fornell and Larcker (1981), we concluded that the measurement model has adequate discriminant validity.

Table 3

Discriminant validity of the measurement model

\begin{tabular}{lccccc}
\hline Variable & $\begin{array}{c}\text { Loyalty } \\
\text { OCB }\end{array}$ & $\begin{array}{c}\text { Participation } \\
\text { OCB }\end{array}$ & $\begin{array}{c}\text { Service Delivery } \\
\text { OCB }\end{array}$ & Staffing & Orientation \\
\hline Loyalty OCB & 0.859 & & & & \\
Participation OCB & 0.732 & 0.830 & & & \\
Service delivery OCB & 0.691 & 0.775 & 0.828 & & \\
Staffing & 0.554 & 0.589 & 0.579 & 0.822 & \\
Orientation & 0.617 & 0.647 & 0.694 & 0.697 & 0.817 \\
\hline
\end{tabular}

Note: Diagonals represent the square root of the average variance extracted while the other entries represent the correlations

Table 4

Cross-loadings

\begin{tabular}{lccccc}
\hline Variable & $\begin{array}{c}\text { Loyalty } \\
\text { OCB }\end{array}$ & $\begin{array}{c}\text { Participation } \\
\text { OCB }\end{array}$ & $\begin{array}{c}\text { Service } \\
\text { Delivery OCB }\end{array}$ & Staffing & Orientation \\
\hline Loyalty OCB 1 & 0.897 & 0.633 & 0.575 & 0.477 & 0.576 \\
Loyalty OCB 2 & 0.902 & 0.648 & 0.637 & 0.479 & 0.552 \\
Loyalty OCB 3 & 0.845 & 0.613 & 0.610 & 0.424 & 0.473 \\
Loyalty OCB 4 & 0.815 & 0.593 & 0.510 & 0.496 & 0.496 \\
Loyalty OCB 5 & 0.831 & 0.655 & 0.634 & 0.497 & 0.542 \\
Participation OCB 6 & 0.660 & 0.853 & 0.668 & 0.553 & 0.536 \\
Participation OCB 7 & 0.601 & 0.856 & 0.642 & 0.481 & 0.529 \\
Participation OCB 8 & 0.587 & 0.877 & 0.648 & 0.511 & 0.523 \\
Participation OCB 9 & 0.562 & 0.837 & 0.650 & 0.406 & 0.517 \\
Participation OCB 10 & 0.613 & 0.718 & 0.601 & 0.477 & 0.567 \\
Service delivery OCB 11 & 0.642 & 0.681 & 0.808 & 0.537 & 0.610 \\
\hline
\end{tabular}


Table 4 (Continued)

\begin{tabular}{lccccc}
\hline Variable & $\begin{array}{c}\text { Loyalty } \\
\text { OCB }\end{array}$ & $\begin{array}{c}\text { Participation } \\
\text { OCB }\end{array}$ & $\begin{array}{c}\text { Service } \\
\text { Delivery OCB }\end{array}$ & Staffing & Orientation \\
\hline Service delivery OCB 12 & 0.641 & 0.723 & 0.801 & 0.509 & 0.547 \\
Service delivery OCB 13 & 0.576 & 0.646 & 0.859 & 0.470 & 0.597 \\
Service delivery OCB 14 & 0.472 & 0.584 & 0.786 & 0.393 & 0.557 \\
Service delivery OCB 15 & 0.571 & 0.627 & 0.862 & 0.468 & 0.567 \\
Service delivery OCB 16 & 0.518 & 0.585 & 0.849 & 0.491 & 0.561 \\
Staffing 1 & 0.464 & 0.436 & 0.436 & 0.812 & 0.590 \\
Staffing 2 & 0.475 & 0.520 & 0.533 & 0.865 & 0.616 \\
Staffing 3 & 0.469 & 0.522 & 0.505 & 0.880 & 0.613 \\
Staffing 4 & 0.455 & 0.466 & 0.446 & 0.800 & 0.482 \\
Staffing 5 & 0.412 & 0.473 & 0.452 & 0.748 & 0.562 \\
Orientation 1 & 0.522 & 0.569 & 0.647 & 0.612 & 0.807 \\
Orientation 2 & 0.485 & 0.525 & 0.559 & 0.550 & 0.799 \\
Orientation 3 & 0.425 & 0.460 & 0.523 & 0.520 & 0.824 \\
Orientation 4 & 0.567 & 0.586 & 0.564 & 0.610 & 0.839 \\
Orientation 5 & 0.503 & 0.482 & 0.526 & 0.542 & 0.816 \\
\hline
\end{tabular}

\section{Structural Model Results}

Prior to testing our proposed hypotheses, the effects of the control variables were estimated. As shown in Table 5, of the seven control variables, age, ethnicity, marital status, and organisational tenure were found to have some significant effects on the endogenous variables. Nevertheless, the R-square change (ranging from 0.005 to 0.017 ) was considered negligible based on Cohen's (1988) interpretation. Therefore, in this investigation, the control variables were excluded from the structural model.

Table 5

Assessment of control variables

\begin{tabular}{|c|c|c|c|c|c|c|c|c|c|}
\hline \multirow{2}{*}{$\begin{array}{l}\text { Control } \\
\text { Variable }\end{array}$} & \multicolumn{3}{|c|}{ Loyalty } & \multicolumn{3}{|c|}{ Service Delivery } & \multicolumn{3}{|c|}{ Participation } \\
\hline & Beta & $t$-value & $\mathrm{R}^{2}$ Change & Beta & $t$-value & $\mathrm{R}^{2}$ Change & Beta & $t$-value & $\mathrm{R}^{2}$ Change \\
\hline Academic & -0.008 & 0.156 & 0.000 & -0.032 & 0.630 & 0.001 & -.057 & 0.855 & 0.003 \\
\hline Age & $0.132 * *$ & 3.274 & 0.017 & 0.056 & 1.262 & 0.003 & 0.046 & 1.149 & 0.002 \\
\hline Ethnic & -0.048 & 0.765 & 0.001 & $-.093 *$ & 2.171 & 0.010 & -.005 & 0.093 & 0.001 \\
\hline Gender & -0.041 & 0.897 & 0.002 & 0.031 & 0.727 & 0.001 & -.045 & 1.084 & 0.002 \\
\hline Marital status & 0.031 & 0.685 & 0.001 & $0.087 *$ & 2.161 & 0.007 & 0.047 & 1.152 & 0.003 \\
\hline Job Tenure & 0.034 & 0.749 & 0.001 & 0.056 & 1.218 & 0.003 & 0.008 & 0.175 & 0.001 \\
\hline Org. Tenure & 0.027 & 0.594 & 0.001 & $0.076^{*}$ & 1.665 & 0.005 & 0.021 & 0.414 & 0.001 \\
\hline
\end{tabular}


We then continued to test our hypotheses. Figure 1 presents the beta coefficients of the proposed relationships. As shown in Figure 1, staffing (involving recruitment and selection) has a positive and significant relationship with loyalty $\mathrm{OCB}(\beta=0.241$, $p>0.01)$, participation OCB $(\beta=0.270, p>0.01)$, and service delivery OCB $(\beta=0.186, p>0.01)$, thereby, lending support for H1a, H1b and H1c. Likewise, our results also provided support for $\mathrm{H} 2 \mathrm{a}, \mathrm{H} 2 \mathrm{~b}$, and $\mathrm{H} 2 \mathrm{c}$. In particular, orientation was found to have a positive and significant relationship with loyalty OCB $(\beta=0.449$, $p>0.01)$, participation $\mathrm{OCB}(\beta=0.459, p>0.01)$, and service delivery OCB $(\beta=0.564, p>0.01)$. The results of the structural model also demonstrated that both staffing (which entails recruitment and selection) and orientation were able to explain $41.0 \%$ of the variance in loyalty $\mathrm{OCB}, 45.5 \%$ in participation $\mathrm{OCB}$, and $49.9 \%$ in service delivery OCB.

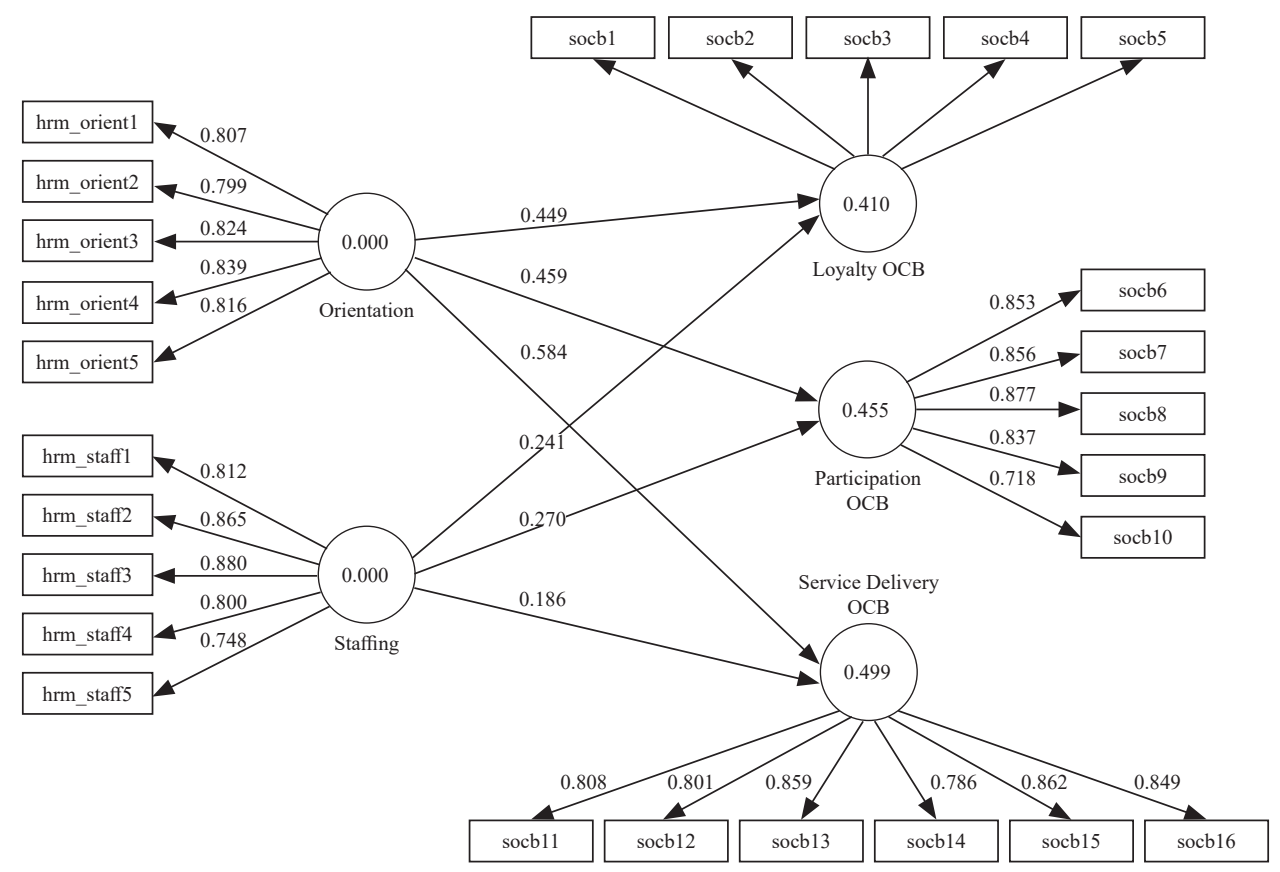

Figure 1. Path Coefficients and R-Square of the Research Model

\section{DISCUSSION, IMPLICATIONS, AND LIMITATIONS}

The present study examined the effects of staffing (consisting of recruitment and selection) and orientation on service-oriented OCBs. Our statistical results provided support for the proposed relationships. Staffing enables the organization to attract the right candidate with desirable qualities (Vlachos, 2008). As previously 
noted by Vlachos (2008), staffing enables the organization to attract the right candidate with desirable qualities. In our study, staffing consist of recruitment and selection. Selective recruitment has been shown to result in satisfied and committed employees (Verquer et al., 2003). On a similar note, a selection process that entails choosing employees on the basis of how well they fit into the overall organization's culture will ensure person-organization fit, leading to greater satisfaction and retention. It has been argued that positive attitudes (in the form of satisfaction and commitment) would be able to stimulate employees to go beyond their call of duty (Bettencourt et al., 2001). According to Morrison (1996), during the selection process, employers and prospective employees exchange information about the type of relationship into which they are entering. A selection process that emphasizes broadly defined obligations and long-term commitment conveys to prospective employees that they are entering into a social exchange relationship, which in turn, is likely to motivate them to reciprocate through greater discretionary extra-role behaviors such as service-oriented OCBs. Furthermore, from customercontact employees' viewpoint, a recruitment and selection process that focuses on individual traits and abilities relating to service excellence would signal to them that such dispositions are highly desired by their organisation, resulting in greater inclination to engage in service-oriented OCBs. Also, a recruitment process that emphasizes internal promotion would be regarded as a supportive practice, which would stimulate employees' feelings of motivation and satisfaction. This, in turn, induces employees to reciprocate through voluntary contributions that benefit the organisation. One such form would be service-oriented OCBs. Our present finding concurs well with the propositions made by Morrison (1996) and the discovery made by Tsaur and Lin (2004).

Additionally, our results revealed that orientation has a positive effect on serviceoriented OCBs. Generally, orientation provides an opportunity for new employees to familiarize themselves with the organization (Louis, 1980). When new employees are able to adapt swiftly to the new environment, they are more likely to experience lower anxiety, thereby, enhancing their motivation and commitment. Such employees would be more likely to perform better and be more willing to spend extra effort for the sake of the organisation. In a similar vein, as suggested by Morrison (1996), through formal orientation, organizations attempts to transmit information concerning its goals as well as instill certain values and expectations of behaviors. Identification with organizational goals is believed to be important precursors to extra-role behaviors as suggested by Morrison (1996). Besides, through orientation programs, new employees learn about the organization's commitment to establish what Blau (1964) termed as long-term social exchange relation. The effect may be a felt obligation to repay the organization through serviceoriented OCBs. Committed employees tend to perform their job well and be more 
willing to expend more effort for the sake of the organization as noted by previous researchers (Klein \& Weaver, 2000; Riordan et al., 2001) leading to an escalation of service-oriented OCBs. Similarly, as stated by Morrison (1996), a socialization process which occurs after a new employee joins an organization can help channel information to new recruits that their employer is committed to building a social exchange relationship. Through the execution of formal orientation programs, new employees can learn and identify themselves with organizational goals and values, which in turn, stimulate them to engage in more OCBs.

Since the hotel industry is a "people business', which means served by people to people (Ekiz et al., 2012), the management of people is a critical agenda. Specifically, it becomes extremely important for hotels to develop effective staffing (consisting of recruitment and selection) and orientation to achieve competitive advantage. Moreover, the interactions between customer-contact employees of the hotel and customers greatly affect the latter's satisfaction and loyalty (Kotler, Bowens, \& Makens, 2010). The findings of the present study indicates that when customercontact employees perceived that the hotel's staffing (in terms of recruitment and selection) and orientation practices are supportive, they would be more likely to enhance the hotel's image and its service (i.e. loyalty OCB), offer more service improvement suggestions aimed at improving the hotel's services (i.e. participation OCB), and behave more conscientiously in fulfilling the needs and expectations of customers (i.e. service delivery $\mathrm{OCB}$ ).

Within the context of Malaysia, our findings proffered support for the validity of Blau's (1964) social exchange theoretical framework in explaining the relationships between specific HRM practices and service-oriented OCBs. Furthermore, from our results, several managerial implications can be tendered. First, since staffing (which include recruitment and selection) has a significant and positive effect on service-oriented OCBs, hotels should focus more attention on their staffing activities. A recruitment process that accentuates certain traits and abilities associated with service excellence suggests the importance placed on such dispositions by the organisation, thereby, increasing the likelihood of employees' performing citizenship behaviours. This would mean that in recruiting candidates, hotel authorities may want to highlight the need for particular personality attributes such as conscientiousness and agreeableness because these two traits have been found by Organ and Lingl (1995) to be valid predictors of citizenship behaviors. Moreover, since the issue of a labor shortage is a norm in the hotel industry (Ahmad \& Scott, 2013), hotels may want to offer more opportunities for internal promotion of existing employees. In this way, employees will be more likely to become motivated to engage in service-oriented OCBs. On a similar note, careful selection through the use of valid tools such as situational interviews would 
ensure a proper match between the applicant and the job requirements (i.e. personorganisation fit), thereby, leading to greater employees' citizenship behaviours. For instance, during the job interview, managers should provide realistic information regarding the job such as long work hours and split shifts. Besides, managers can inform applicants about the hotel's service culture, and the need to hire employees for the hotel rather than for a particular job. In this way, employees may attempt to understand the importance of providing outstanding service. Furthermore, the management of hotels should strive to continuously implement formal orientation programs to new employees. The information and skills that new recruits acquire during orientation would increase their understanding of organisational values and goals, leading to higher motivation and commitment, which ultimately result in greater service-oriented OCBs. Within a hotel service environment, individualised socialisation tactics through the use of mentors may help reduce new employees' level of uncertainty with regards to their work roles, which in turn, elevate their morale and satisfaction.

As with all studies, there are limitations to this research. First, our data was cross-sectional, which limits our ability to make causal inferences. Thus, a future longitudinal approach could cross-validate the current findings and provide additional support regarding the causality of the HRM practices-service-oriented OCBs linkage. Second, this study was confined to frontline employees working in the hotel industry in Peninsular Malaysia. To increase the generalisability of the findings, we thus call for more studies to consider other service sectors such as banking, healthcare, and education. It would also be interesting if future researchers would expand this line of investigation to other developing countries.

\section{ACKNOWLEDGEMENT}

The authors would like to express their gratitude to Universiti Sains Malaysia for providing the grant (1001/PMGT/816193) to fund this research. 


\section{APPENDIX A}

\section{List of Measurement Items}

\section{Service Oriented Organisational Citizenship Behaviour}

Over the past year, ....

\section{Loyalty OCB}

1 I would like to tell outsiders that this hotel is a good place to work.

2 I often say good things about this hotel to others.

3 I generate favourable goodwill for this hotel.

4 I encourage my friends and family to use the products (i.e. rooms, food and beverage menus) and services (i.e. Spa package) of this hotel.

5 I actively promote the hotel's products (i.e. rooms, food and beverage menus) and services (i.e. Spa package) of this hotel.

\section{Participation OCB}

1 I encourage my coworkers to contribute ideas and suggestions for service improvement in this hotel.

2 I contribute many ideas for customer promotions and communications.

3 I make constructive suggestions for service improvement.

4 I frequently present to others creative solutions to customer problems.

5 I take home brochures to read up on products and services of this hotel.

\section{Service Delivery OCB}

1 I follow customer service guidelines as best as possible.

2 I conscientiously follow guidelines for promotions.

3 I follow up in a timely manner to customer request and problems.

4 I perform duties with unusually few mistakes.

5 I always have a positive attitude at work.

6 Regardless of circumstances, I am exceptionally courteous and respectful to customers.

\section{Staffing}

1 This hotel selects the best candidate when recruiting employees.

2 This hotel places priority on candidates' potentials to learn when recruiting employees.

3 Recruitment in this hotel emphasizes traits and abilities required for providing a high quality of customer services.

4 In this hotel, internal candidates have the priority for job openings.

5 In this hotel, qualified employees have good opportunities for promotion.

\section{Orientation}

1 This hotel requires employees to participate in a formal orientation program.

2 This hotel provides a structured mentoring program for employees.

3 In the orientation for new incomers, this hotel discusses its values and culture.

4 This hotel gives proper and official courses in preparation of the employees at their jobs. 


\section{REFERENCES}

Ahmad, R., \& Scott, N. (2013). Managing the front office department: Staffing issues in Malaysian Hotels. Anatolia: An International Journal of Tourism and Hospitality Research, 1-15.

Allen, N. J., \& Meyer, J. P. (1990). Organizational socialization tactics: A longitudinal analysis of links to newcomers' commitment and role orientation. Academy of Management Journal, 33(4), 847-858. https://doi.org/10.2307/256294

Allen, D. G., Shore, L. M., \& Griffeth, R. W. (2003). The role of perceived organizational support and supportive human resource practices in the turnover process. Journal of Management, 29(1), 99-118. https://doi.org/10.1177/014920630302900107

Atteya, N. M. (2012). Testing the impact of the human resource management practices on job performance: An empirical study in the Egyptian joint venture petroleum companies. International Journal of Business and Social Science, 3(9), 105-119.

Baum, T., \& Devine, F. (2007). Skills and training in the hotel sector: The case of front office employment in Northern Ireland. Tourism and Hospitality Research, 7(3/4), 269-280. https://doi.org/10.1057/palgrave.thr.6050046

Bernardin, H., \& Russell, J. (2007). Human resource management: An experiential approach (4th ed.). New York, USA: The McGraw-Hill Companies Inc.

Bettencourt, L. A., Gwinner, K. P., \& Meuter, M. L. (2001). A comparison of attitude, personality, and knowledge predictors of service-oriented organizational citizenship behaviors. Journal of Applied Psychology, 86(1), 29-41. https://doi. org/10.1037/0021-9010.86.1.29

Bienstock, C. C., DeMoranville, C. W., \& Smith, R. K. (2003). Organizational citizenship behavior and service quality. The Journal of Services Marketing, 17(4/5), 357378. https://doi.org/10.1108/08876040310482775

Blau, P. M. (1964). Exchange and power in social life. New York, USA: Wiley.

Bolino, M. C., \& Turnley, W. H. (2005). The personal costs of citizenship behavior: The relationship between individual initiative and role overload, job stress, and workfamily conflict. Journal of Applied Psychology, 90(4), 740-748. https://doi. org/10.1037/0021-9010.90.4.740

Boon, C., Belschak, F. D., Den Hartog, D. N., \& Pijnenburg, M. (2014). Perceived human resource management practices: Their effect on employee absenteeism and time allocation at work. Journal of Personnel Psychology, 13(1), 21-33. https://doi. org/10.1027/1866-5888/a000101

Chang, P-C., \& Chen, S-J. (2011). Crossing the level of employee's performance: HPWS, affective commitment, human capital, and employee job performance in professional service organizations. The International Journal of Human Resource Management, 22(4), 883-901. https://doi.org/10.1080/09585192.2011.555130

Chin, W. W. (1998). The partial least squares approach for structural equation modeling. Modern methods for business research. In G. A. E. Marcoulides (Ed.), Methodology for business and management (pp. 295-336). USA: Lawrence Erlbaum. 
Chuang, C-H., \& Liao, H. (2010). Strategic human resource management in service context: Taking care of business by taking care of employees and customers. Personnel Psychology, 63(1), 153-196. https://doi.org/10.1111/j.1744-6570.2009.01165.x

Cohen, J. (1988). Statistical power analysis for the behavioral sciences (2nd ed.). Hillsdale, NJ: Lawrence Erlbaum.

Cooper-Thomas, H. D., \& Anderson, N. (2006). Organizational socialization: A new theoretical model and recommendations for future research and HRM practices in organizations. Journal of Managerial Psychology, 21(5), 492-516. https://doi. org/10.1108/02683940610673997

Coway, J. M., \& Lance, C. E. (2010). What reviewers should expect from authors regarding common method bias in organizational research. Journal of Business and Psychology, 25(2010), 325-334. https://doi.org/10.1007/s10869-010-9181-6

Delery, J. E., \& Doty, D. H. (1996). Modes of theorizing in strategic human resource management: Tests of universalistic, contingency, and configurational performance predictions. Academy of Management Journal, 39(4), 802-835. https://doi.org/10.2307/256713

Ekiz, E., Khoo-Lattimore, C., \& Memarzadeh, F. (2012). Air the anger: Investigating online complaints on luxury hotels. Journal of Hospitality and Tourism Technology, 3(2), 96-106. https://doi.org/10.1108/17579881211248817

Fiorito, J., Bozeman, D. P., Young, A., \& Meurs, J. A. (2007). Organizational commitment, human resource practices, and organizational characteristics. Journal of Managerial Issues, 19(2), 186-207.

Fornell, C., \& Larcker, D. F. (1981). Evaluating structural equation models with unobservable variables and measurement error. Journal of Marketing Research, 18(1), 39-50. https://doi.org/10.2307/3151312

González, J. V., \& Garazo, T. G. (2006). Structural relationships between organizational service orientation, contact employee job satisfaction and citizenship behavior. International Journal of Service Industry Management, 17(1), 23-50. https://doi.org/10.1108/09564230610651561

Greene, C. N., \& Organ, D. W. (1973). An evaluation of causal models linking the received role with job satisfaction. Administrative Science Quarterly, 18(1), 95-103. https://doi.org/10.2307/2391931

Hair, J. F., Ringle, C. M, \& Sarstedt, M. (2011). PLS-SEM: Indeed a silver bullet. Journal of Marketing Theory and Practice, 18(2), 139-152. https://doi.org/10.2753/ MTP1069-6679190202

Hair, J. F., Hult, G. T. M., Ringle, C. M., \& Sarstedt, M. (2014). A primer on partial least squares structural equation modeling (PLS-SEM). Thousand Oaks, CA: Sage.

Hartline, M. D., \& Jones, K. C. (1996). Employee performance cues in a hotel service environment: Influence on perceived service quality, value, and word-ofmouth intentions. Journal of Business Research, 35(3), 207-215. https://doi. org/10.1016/0148-2963(95)00126-3

Hayes, D. K., \& Ninemeier, J. D. (2009). Human resources management in the hospitality industry. New Jersey: John Wiley \& Sons, Inc.

Hoque, K. (1999). Human resource management in the hotel industry: strategy, innovation, and performance. London, GBR: Routledge. 
Huselid, M. A. (1995). The impact of human resource management practices on turnover, productivity, and corporate financial performance. Academy of Management Journal, 38, 635-672. https://doi.org/10.2307/256741

Karatepe, O. M., \& Uludag, O. (2008). Supervisor support, work-family conflict, and satisfaction outcomes: An empirical study in the hotel industry. Journal of Human Resources in Hospitality \& Tourism, 7(2), 115-134. https://doi. org/10.1080/15332840802156824

Klein, H. J., \& Weaver, N.A. (2000). The effectiveness of an organizational-level orientation training program in the socialization of new hires. Personnel Psychology, 53(1), 47-66. https://doi.org/10.1111/j.1744-6570.2000.tb00193.x

Kotler, P., Bowen, J., \& Makens, J. (2010). Marketing for hospitality and tourism (5th ed.), New Jersey: Prentice-Hall.

Kusluvan, S., Kusluvan, Z., Ilhan, I., \& Buyruk, L. (2010). The human dimension: A review of human resources management issues in the tourism and hospitality industry. Cornell Hospitality Quarterly, 51(2), 171-214. https://doi.org/10.1177/ 1938965510362871

Lin, S-J. J., \& Lin, S-C. (2011). Moderating effect of organizational climate on the relationship of organizational support and service-oriented organizational citizenship behaviors. African Journal of Business Management, 5(2), 582-595.

Louis, M. R. (1980). Surprise and sense making: What newcomers experience in entering unfamiliar organizational settings. Administrative Science Quarterly, 25(2), 226251. https://doi.org/10.2307/2392453

Ma, E., \& Qu, H. (2011).Social exchanges as motivators of hotel employees' organizational citizenship behavior: The proposition and application of a new three-dimensional framework. International Journal of Hospitality Management, 30(3), 680-688. https://doi.org/10.1016/j.ijhm.2010.12.003

Maroudas, L., Kyriakidou, O., \& Vacharis, A. (2008). Employees' motivation in the luxury hotel industry: The perceived effectiveness of human-resource practices. Managing Leisure, 13(3/4), 258-271. https://doi.org/10.1080/ 13606710802200969

Mathis, R. L., \& Jackson, J. H. (2000). Human resource management. Cincinnati, OH: Southwestern College Publishing.

Ministry of Tourism and Culture Malaysia (2014). Malaysia registers 25.7 million tourists and RM65.44 billion tourist receipts in 2013. Retrieved February 28, 2014, from Ministry of Tourism and Culture Malaysia: http:/www.motac.gov.my/en/ archives/2014/160-malaysia-registers-257-million-tourists-and-rm6544-billiontourist-receipts-in-2013

Ministry of Tourism and Culture Malaysia (2015). History of Visit Malaysia Year. Retrieved January 20, 2015, from Years of Festival 2015: http://myfest2015.com.my/aboutmyfest-2015/history-of-visit-malaysia-year

Ministry of Tourism (2012). Malaysia Accommodation Directory 2010/2011, H. Unit, Editor 2012, Tourism Malaysia, Ministry of Tourism: Kuala Lumpur.

Morrison, A. (2000). Developing a global leadership model. Human Resource Management, 39(2\&3), 117-131. https://doi.org/10.1002/1099-050X(200022/23) $39: 2 / 3<117::$ AID-HRM3 $>3.0$. CO $2-1$ 
Morrison, E. W. (1996). Organizational citizenship behavior as a critical link between HRM practices and service quality. Human Resource Management, 35(4), 493512. https://doi.org/10.1002/(SICI)1099-050X(199624)35:4<493::AID-HRM4> 3.0.CO;2-R

Nasurdin, A. M., Tan, C. L., \& Low, S. F. (2011). Service-oriented organizational citizenship behavior: Assessing the predictive role of human resource management practices. International Journal of Arts \& Sciences, 4(9), 381-394.

Organ, D. W. (1988). Organizational citizenship behavior: The good soldier syndrome. Lexington: MA: Lexington Books.

Organ, D. W., \& Konovsky, M. (1989). Cognitive versus affective determinants of organizational citizenship behavior. Journal of Applied Psychology, 74(1), 157164. https://doi.org/10.1037/0021-9010.74.1.157

Organ, D. W., \& Lingl, A. (1995). Personality, satisfaction, and organizational citizenship behavior. Journal of Social Psychology, 135, 339-350. https://doi.org/10.1080/0 0224545.1995.9713963

Podsakoff, P. M., MacKenzie, S. B., Lee, J-Y, \& Podsakoff, N. P. (2003). Common method biases in behavioral research: A critical review of the literature and recommended remedies. Journal of Applied Psychology, 88(5), 879-903. https://doi.org/10.1037/0021-9010.88.5.879

Podsakoff, P. M., \& Organ, D. W. (1986). Self-reports in organizational research: Problems and prospects. Journal of Management, 12(2), 531-544. https://doi. org/10.1177/014920638601200408

Ramachandran, Y., Jordan, P. J., Troth, A. C., \& Lawrence, S. A. (2011). Emotional intelligence, emotional labor and organizational citizenship behavior in service environments. International Journal of Work Organisation and Emotion, 4(2), 136-157. https://doi.org/10.1504/IJWOE.2011.044594

Riordan, C. M., Weatherly, E. W., Vandenberg, R. J., \& Self, R. M. (2001). The effects of pre-entry experiences and socialization tactics on newcomer attitudes and turnover. Journal of Managerial Issues, 13(2), 159.

Rogg, K. L., Schmidt, D. B., Shull, C., \& Schmitt, N. (2001). Human resource practices, organizational climate, and customer satisfaction. Journal of Management, 27(4), 431-449. https://doi.org/10.1177/014920630102700403

Snape, E., \& Redman, T. (2010). HRM practices, organizational citizenship behavior, and performance: A multi-level analysis. Journal of Management Studies, 47(7), 1219-1247.

Solnet, D., \& Hood, A. (2008). Generation Y as hospitality employees: Framing a research agenda. Journal of Hospitality and Tourism Management, 15, 59-68. https://doi. org/10.1375/jhtm.15.59

Sun, L-Y., Aryee, S., \& Law, K. S. (2007). High-performance human resource practices, citizenship behavior, and organizational performance: A relational perspective. Academy of Management Journal, 50(3), 558-577. https://doi.org/10.5465/AMJ. 2007.25525821 
Tang, T. W., \& Tang, Y. Y. (2012). Promoting service-oriented organizational citizenship behaviors in hotels: The role of high-performance human resource practices and organizational social climates. International Journal of Hospitality Management, 31(3), 885-895. https://doi.org/10.1016/j.ijhm.2011.10.007

Tanke, M. L. (2001). Human resources management for the hospitality industry (2nd ed.). United States: Thomson Learning.

Tourism Malaysia (2014). Tourism Publications Provide Insight into Malaysia's Tourism Performance. Retrieved March 20, 2014 from Tourism Malaysia: http://corporate. tourism.gov.my/media/view/tourism-publications-provide-insight-into-malaysias-tourism-performance

Tsai, C. T. S., \& Su, C. S. (2011). Leadership, job satisfaction and service-oriented organizational citizenship behaviors in flight attendants. African Journal of Business Management, 5(3), 1915-1926.

Tsaur, S-H., \& Lin, Y-C. (2004). Promoting service quality in tourist hotels: The role of HRM practices and service behavior. Tourism Management, 25(4), 471-481. https://doi.org/10.1016/S0261-5177(03)00117-1

Verquer, M. L., Beehr, T. A., \& Wagner, S. H. (2003). A meta-analysis of relations between person-organization fit and work attitudes. Journal of Vocational Behavior, 63(3), 473-489. https://doi.org/10.1016/S0001-8791(02)00036-2

Vlachos, I. (2008). The effect of human resource practices on organizational performance: Evidence from Greece. International Journal of Human Resource Management, 19(1), 74-97. https://doi.org/10.1080/09585190701763933

Wang, M-L. (2009a). Does organizational support promote citizenship in service settings? The moderating role of service climate. Journal of Social Psychology, 149(6), 648-676. https://doi.org/10.1080/00224540903347297

Wang, M-L. (2009b). What makes a good citizen in service settings? Service Industries Journal, 29(5), 621-634. https://doi.org/10.1080/02642060902720055

Wang, L. (2010). Does organizational support promote citizenship? The moderating role of market-focused HRM. The Service Industries Journal, 30(7), 1077-1095. https://doi.org/10.1080/02642060802298368

Wanous, J. P., \& Reichers, A. E. (2000). New employee orientation programs. Human Resource Management Review, 10(4), 435-451. https://doi.org/10.1016/S10534822(00)00035-8

Wayne, S. J., Shore, L. M., \& Liden, R. C. (1997). Perceived organizational support and leader-member exchange: A social exchange perspective. Academy of Management Journal, 40(1), 82-111. https://doi.org/10.2307/257021

Whitener, E. M. (2001). Do "high commitment" human resource practices affect employee commitment? A cross-level analysis using hierarchical linear modeling. Journal of Management, 27, 515-535. https://doi.org/10.1177/014920630102700502

Yang, Y-C. (2011). High-involvement human resource practices, affective commitment, and organizational citizenship behaviors in service setting. The Service Industries Journal, 32(8), 1209-1227. https://doi.org/10.1080/02642069.2010.545875

Yoon, M. H., \& Suh, J. (2003). Organizational citizenship behaviors and service quality as external effectiveness of contact employees. Journal of Business Research, 56, 597-611. https://doi.org/10.1016/S0148-2963(01)00290-9 
